\title{
Retrovirus gag protein p30 in the islets of non-obese diabetic mice: relevance for pathogenesis of diabetes mellitus
}

\author{
C.Nakagawa ${ }^{1}$, T.Hanafusa ${ }^{1}$, J.Miyagawa ${ }^{1}$, M. Yutsudo ${ }^{2}$, H.Nakajima ${ }^{1}$, K. Yamamoto ${ }^{1}$, K. Tomita $^{1}$, N. Kono ${ }^{1}$, \\ A.Hakura ${ }^{2}$ and S. Tarui ${ }^{3}$ \\ ${ }^{1}$ The Second Department of Internal Medicine, Osaka University Medical School, ${ }^{2}$ Department of Tumour Virology, Research Institute \\ for Microbial Diseases, Osaka University, and ${ }^{3}$ Otemae Hospital, Osaka, Japan
}

Summary. We investigated the presence of retroviral protein in the pancreatic islets of non-obese diabetic mice to prove that the virus-like particle observed specifically in the pancreatic Beta cell of these mice was retrovirus. Western blot analysis probed with anti-retrovirus antibody demonstrated the existence of retroviral gag (group specific antigen) protein $\mathrm{p} 30$ in the islets of female non-obese diabetic mice. Islets of non-obese diabetic mice which were treated with cyclophosphamide, known to accelerate the development of insulitis and diabetes mellitus, have shown both a significantly increased number of retrovirus-like particles (type $\mathrm{C}$ ) and enhanced expression of gag protein $\mathrm{p} 30$, compared to those of mice not treated with cyclophosphamide. These results confirmed the presence of type $\mathrm{C}$ retrovirus in non-obese diabetic mouse Beta cells and suggest a role for retrovirus in the development of insulitis and diabetes in these mice.

Key words: Non-obese diabetic (NOD) mice, retrovirus, gag protein $\mathrm{p} 30$, autoimmunity, cyclophosphamide, pathogenesis, Western blot analysis, ultrastructure.
Accumulating circumstantial evidence suggests a role of viruses in the pathogenesis of Type 1 (insulin-dependent) diabetes mellitus. We have previously demonstrated by electron microscopy and by immunohistochemistry the presence of retrovirus-like particles in the pancreatic Beta cells of non-obese diabetic (NOD) mice, an animal model of human Type 1 diabetes $[1,2]$. However, proof of the presence of retrovirus-derived protein in the islets of the NOD mouse remained to be demonstrated. Thus, we investigated by Western blot analysis whether the protein derived from retrovirus was present specifically in the islets of NOD mice. We then studied whether the amount of the protein was increased in NOD mice treated with cyclophosphamide (CY) which is known to accelerate the development of insulitis and diabetes in the NOD mouse [3], to further clarify a role of the retrovirus for diabetes.

\section{Materials and methods}

\section{Animals}

An NOD/shi mouse colony was produced from several mice originally purchased from Clea Japan Inc. (Tokyo, Japan) and supplied by the Supply Center of Inbred Animals at Osaka University. ICR/Jcl mice were purchased from Clea Japan Inc.

\section{Cyclophosphamide treatment}

One hundred and ten female NOD mice aged 6-17 weeks were injected intraperitoneally with CY (Shionogi Pharmaceutical Co. Ltd., Osaka, Japan) at a dose of $150 \mathrm{mg} / \mathrm{kg}$ body weight, twice with a 3-day interval between injections. Ninety NOD and 60 ICR mice, matched for age and sex with the CY-injected NOD mice, were used as controls. The control mice were injected with $154 \mathrm{mmol} / \mathrm{l} \mathrm{NaCl}$ instead of CY. In our NOD mouse colony, CY treatment significantly increased the incidence of insulitis after 2 weeks. However, the severity of lymphocyte infiltration was mild to moderate; thus the number of remaining Beta cells was sufficient for the following analysis.

\section{Electron microscopy}

Two weeks after the second injection of CY or $154 \mathrm{mmol} / \mathrm{N} \mathrm{NaCl}$, five 8-week-old female NOD mice from each group were perfused via the left ventricle with $3.0 \%$ glutaraldehyde in $0.1 \mathrm{~mol} / 1 \mathrm{Millonig's}$ phosphate buffer at $\mathrm{pH}$ 7.4. The pancreas was removed, cut into small pieces, and immersed in the same fixative for $2 \mathrm{~h}$ at $4^{\circ} \mathrm{C}$. The tissues were then post-fixed with $1.0 \% \mathrm{OsO}_{4}$ in $0.1 \mathrm{~mol} / 1$ Millonig's phosphate buffer at $\mathrm{pH} 7.4$ for $1 \mathrm{~h}$ at $4^{\circ} \mathrm{C}$. After dehydration with graded concentrations of ethanol, the pancreatic tissues were embedded in Epon epoxy resin. Ultra-thin sections (70$80 \mathrm{~nm}$ thick) cut on a Reichert-Yung ultramicrotome were doubly stained with $3.0 \%$ aqueous uranyl acetate and Reynolds' lead citrate, and were examined with a JOEL 100-CX type electron microscope. 


\section{Islet isolation}

Islets were isolated from CY-treated NOD mice, CY-untreated NOD mice and ICR mice. Islets of CY-treated NOD mice were isolated 10 to 14 days after the $C Y$ injection. Pancreases were removed, cut into small pieces, and digested with collagenase (Type 4, Worthington Biomedical Co., Freehold, NJ, USA, $5 \mathrm{mg} / \mathrm{ml}$ in RPMI 1640) for $15 \mathrm{~min}$ at $37^{\circ} \mathrm{C}$ with shaking. After washing, islets were handpicked. About 4000 islets were collected in each of the three groups of mice.

\section{Western blot analysis}

Islets were homogenized in RIPA solution $(0.05 \mathrm{~mol} / \mathrm{T}$ Tris- $\mathrm{HCl}$, $0.15 \mathrm{~mol} / 1 \mathrm{NaCl}, 1 \%$ Triton $\mathrm{X}-100,1 \%$ deoxycholate, $0.1 \%$ sodium dodecyl sulphate [SDS], 150 kallikrein inhibitor unit (KIU)/ml aprotinin, $\mathrm{pH} 7.5$ ) with a glass homogenizer and then centrifuged at $15000 \mathrm{~g}$ for $30 \mathrm{~min}$ at $4^{\circ} \mathrm{C}$, after which the cell debris was removed. As a positive control, Moloney murine leukaemia virus (Mo-MuLV) or cell lysate of National Institutes of Health (NIH) 3T3 fibroblasts infected with Mo-MuLV was used.

Since the amount of retroviral protein contained in the pancreatic islet-homogenate of NOD mice was considered to be very small, it was necessary to separate the retroviral protein from islethomogenate as effectively as possible. For this purpose, two methods, immunoprecipitation and trichloroacetic acid (TCA) treatment [4], were employed at the first step of separation.

As anti-retrovirus antibody, anti-Rauscher leukaemia virus p30 antiserum, anti-AKR virus $\mathrm{p} 30$ antiserum, anti-BALB V-2 virus $\mathrm{p} 30$ antiserum, anti-Gross leukaemia virus p30 antiserum, and anti-Kirsten murine sarcoma virus $\left(\mathrm{NIH}_{\text {xeno }}\right)$ antiserum, all derived from goat, were used. All of these react with the gag protein $\mathrm{p} 30$. The genomic structure of all retroviruses is mainly composed of three genes: gag, which encodes the core protein; pol, which encodes the reverse transcriptase and polymerase; and env, which encodes the viral envelope proteins. Among these three genes, the gag gene is considered to be most conserved and its base sequence is very similar in all retroviruses. In addition, the antigenicity of gag protein is also similar within the species. Thus, to investigate the unknown retrovirus, we used the antibody for $\mathrm{p} 30$ which was one of the main products of the gag gene. As a control, normal goat serum was used.

\section{1) Immunoprecipitation}

The homogenate of islets ( $40 \mu \mathrm{g}$ protein) was incubated with a mixture of all anti-retrovirus antisera for $16 \mathrm{~h}$ at $4^{\circ} \mathrm{C}$. Protein $\mathrm{G}$ sepharose $C L A B$ was then added to the incubation mixture and the beads were recovered by centrifugation. Proteins bound to the beads were separated by $10-20 \%$ SDS-PAGE according to the method of Laemmli [5] and transferred onto Immobilon P (polyvinylidene difluoride microporous membrane; Millipore Co., Bedford, Mass., USA) by a Poly Blot apparatus according to the manufacturer's recommendation (American Bionetics, Hayward, Calif., USA). After blocking with $5 \%$ skimmed milk in TBST $(0.01 \mathrm{~mol} / \mathrm{l}$ Tris- $\mathrm{HCl}$, $0.15 \mathrm{~mol} / \mathrm{l} \mathrm{NaCl}, 0.05 \%$ Tween 20 ), the filter was incubated for $16 \mathrm{~h}$ at $4^{\circ} \mathrm{C}$ with the same anti-retrovirus antisera, diluted to 1:800, as was used for immunoprecipitation. The proteins were detected by two methods, autoradiography and enzyme immunochemistry. In the autoradiographic method, the filter was incubated with ${ }^{125}$ I-labelled protein G (Amersham, Amersham, Bucks, UK) and exposed to an $\mathrm{X}$-ray film for 4 days at $-70^{\circ} \mathrm{C}$. In the enzyme immunochemical method, the filter was incubated with biotinylated donkey antisheep/goat Ig (Amersham) diluted to 1:400. After washing, the filter was incubated with streptavidin-alkaline phosphatase (Gibco BRL Inc., Gaitherburg, Md., USA) and then with substrates (nitroblue tetrazolium chloride, 5-bromo-4-chloro-3-indolylphosphate p-toluidine salt, Lavamisole solution (Vector Laboratories Inc., Burlin- game, Calif., USA $)$ in AP buffer $(0.1 \mathrm{~mol} / 1$ Tris- $\mathrm{HCl}, 0.1 \mathrm{~mol} / \mathrm{N} \mathrm{NaCl}$, $0.05 \mathrm{~mol} / \mathrm{l} \mathrm{MgCl}_{2}, \mathrm{pH} 9.5$ ).

\section{2) Trichloroacetic acid (TCA) treatment}

The homogenates of islets ( $5 \mu \mathrm{g}$ protein) were incubated for $1 \mathrm{~h}$ at $4{ }^{\circ} \mathrm{C}$ with TCA at a final concentration of $10 \%$. The reaction mixture was then centrifuged and the supernatant was removed. After washing with acetone, the pellet was separated by SDS-PAGE as described above and transferred onto nitrocellulose membrane. As anti-retrovirus antibody, anti-Rauscher leukaemia virus p30 antiserum was used because it showed the highest activity against positive control in a preliminary experiment. This antiserum was also used as a pre-absorbed antibody in place of anti-retrovirus antiserum after pre-absorption with Mo-MuLV. The reaction was visualized by enzyme immunochemistry as described above.

Liver and spleen of NOD mice were also homogenized in RIPA buffer and examined in a similar manner.

\section{Statistical analysis}

For statistical analysis, five blocks of the islets from each mouse were randomly selected (a total of 25 islets in each group) and only the Beta cells which possessed nuclei in the sections were observed. The percentage of the Beta cells in which virus particles with a feature of type $C$ retrovirus were recognized was calculated from the total number of the Beta cells examined. The average number of these particles in virus particle-containing Beta cell was also calculated in each group. Statistical analysis was made by Student's $t$ test.

\section{Results}

Retrovirus-like particles were observed specifically in the Beta cells by electron microscopy. These virus particles were localized in the cisternae of rough endoplasmic reticulum, and could not be observed in the cytoplasmic matrix of Beta cells (Fig. 1 a). Most of the particles were circular in shape ( $85-120 \mathrm{~nm}$, outer diameter), and had the electron-lucent or slightly electron-dense core surrounded by a ring-shaped, membrane-like structure which probably corresponds to the nucleocapsid. These particles were enclosed by an outer envelope which showed the unit membrane structure. Between the envelope and the ring-shaped nucleocapsid, the space occupied by granular or filamentous materials was usually seen (Fig. 1b). Some of the particles were rod-like or cylindrical in shape and the length of such particles was less than $1.2 \mu \mathrm{m}$ (Fig. $1 \mathrm{c}$ ). Particles budding from the limiting membrane of rough endoplasmic reticulum into the cisternae were sometimes recognized. The limiting membrane was continuous to the envelope of the budding particle (Fig. 1d). Thus, most of the particles (more than $90 \%$ of the virus-like particles) were considered to be type $\mathrm{C}$ retroviruses, although the budding phenomenon was only seen at the limiting membrane of rough endoplasmic reticulum. However, it was difficult to determine whether all of the virus-like particles were type $\mathrm{C}$ or not, because some of the particles appeared to be immature, or not enough of the particle was included in the ultra-thin (70$80 \mathrm{~nm}$ ) sections. 

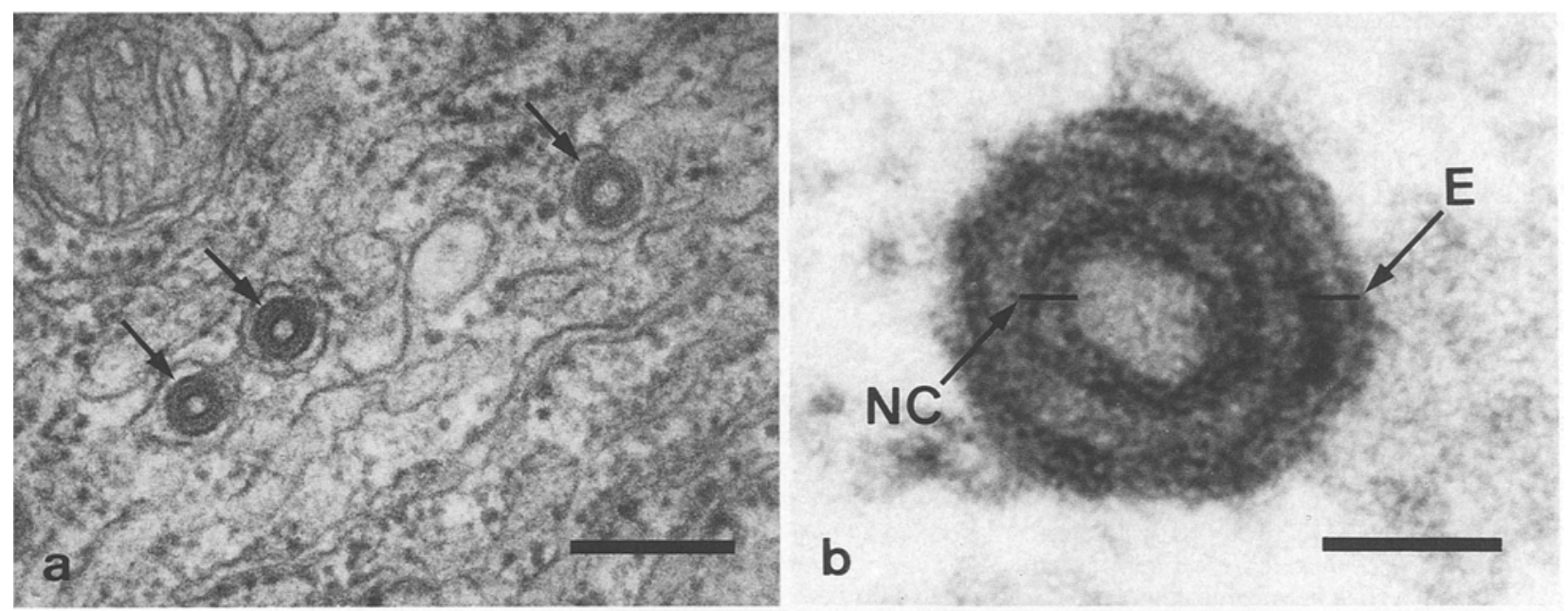

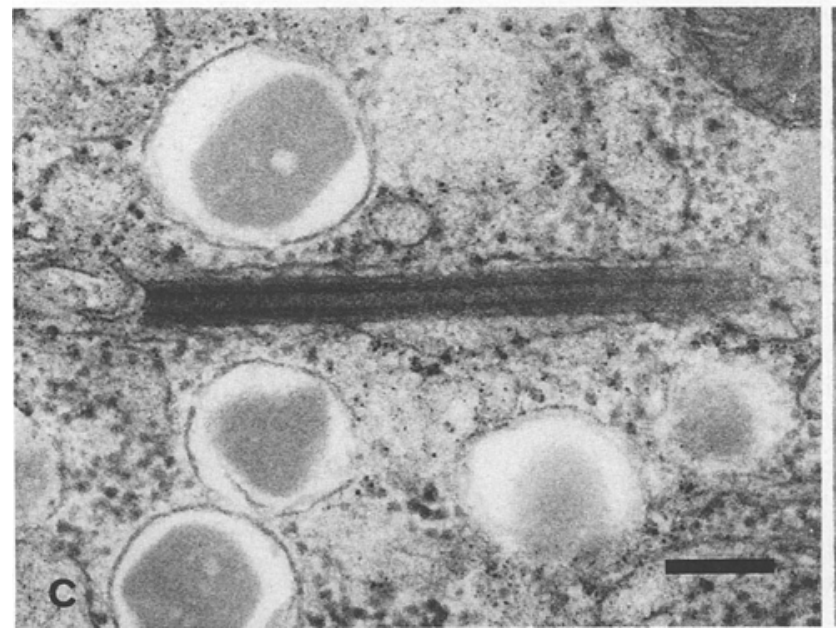

Fig.1. a Retrovirus-like particles in a Beta cell of the non-obese diabetic (NOD) mouse ( 8 weeks of age). The particles can be seen in the cisternae of rough endoplasmic reticulum. Many of the particles are circular in shape (arrows) and these particles (85-120 nm in diameter) have electron-lucent or slightly electron-dense cores $(50$ $80 \mathrm{~nm}$ in outer diameter $)$. The bar represents $0.2 \mu \mathrm{m} .(\times 86500)$ b A higher magnification of retrovirus-like particle (type $\mathrm{C}$ ). The virus particle is enclosed by an envelope (E) which shows unit membrane structure (double leaflets). Inside the envelope, ring-shaped, membrane-like structure (NC, nucleocapsid) packed with amorphous or

The percentage of the Beta cells containing virus particles which showed a feature of type C retrovirus was significantly higher $(p<0.01)$ in CY-treated NOD mice $(29.2 \pm 7.1 \%)$ than that in CY-untreated NOD mice $(10.4 \pm 3.2 \%)$. Furthermore, the average number of particles in virus particle-containing Beta cells was also significantly higher $(p<0.01)$ in CY-treated NOD mice $(8.2 \pm 3.6)$ than that in CY-untreated NOD mice $(1.8 \pm 0.5)$ (Mean \pm SEM).

Western blot analysis of positive controls showed a $30 \mathrm{kDa}$ protein, confirming the reliability of our method. Western blot analysis of islet homogenate demonstrated the presence of $30 \mathrm{kDa}$ protein in pancreatic islets of NOD mice without CY treatment (Fig.2a). To clarify whether this $30 \mathrm{kDa}$ protein was derived from retroviruses, we performed Western blot analysis of the TCAtreated islet homogenate of NOD mice with or without

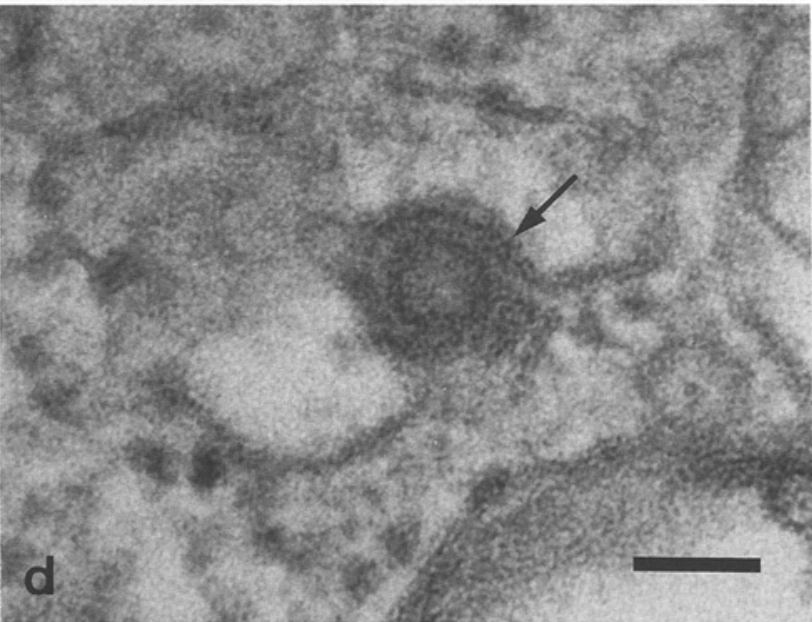

filamentous materials can be recognized. The bar represents $50 \mathrm{~nm}$. $(\times 376500)$ c Virus-like particle of rod or cylindrical shape in a Beta cell of the NOD mouse ( 8 weeks of age). This particle is about $1.2 \mu \mathrm{m}$ long and has a long cylindrical core. The bar represents $0.2 \mu \mathrm{m}$. ( $\times 54500)$ d A virus particle budding from a limiting membrane of rough endoplasmic reticulum into the cisterna. Note that the envelope is continuous to the limiting membrane of rough endoplasmic reticulum (arrow). The bar represents $50 \mathrm{~nm}$. $(\times 247200)$

CY treatment using anti-retrovirus antibody or the antibody pre-absorbed with Mo-MuLV. The $30 \mathrm{kDa}$ protein was also detected with the antibody, whereas it was not detected with the absorbed antibody in either CY-treated or CY-untreated NOD mice (Fig. 2 c, d: lane B, A).

The effect of CY treatment on the expression of the $30 \mathrm{kDa}$ protein was further investigated. The visualization by autoradiography in conjunction with the immunoprecipitation was employed for this purpose. A preliminary experiment has shown that this method was less sensitive than the enzyme immunochemical visualization. As a result, this $30 \mathrm{kDa}$ protein was detected in CY-treated NOD mice but not in CY-untreated NOD mice (Fig. 2b). This result indicated that $\mathrm{CY}$ treatment increased the expression of retrovirus $g a g$ protein $\mathrm{p} 30$.

Western blot analysis probed with normal goat serum instead of anti-retrovirus antiserum showed no $30 \mathrm{kDa}$ 


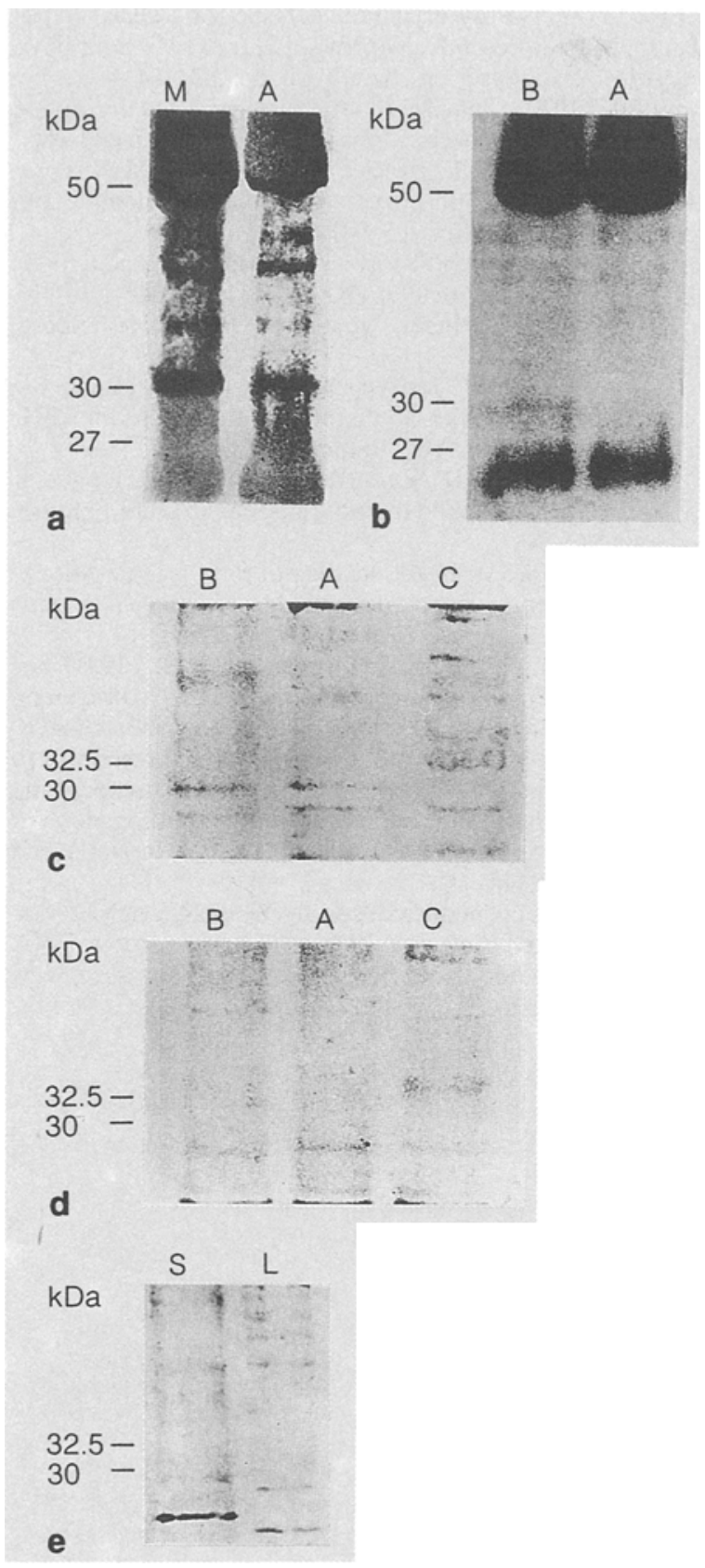

Fig. 2a-e. Western blot analysis of the immunoprecipitated nonobese diabetic (NOD) mouse islet homogenate probed with antiretrovirus antisera ( $\mathbf{a}$ and $\mathbf{b}$ ), and Western blot analysis using the trichloroacetic acid (TCA)-treated islet homogenate probed with anti-retrovirus antiserum (c) and anti-retrovirus antiserum preabsorbed with Moloney-murine leukaemia virus (Mo-MuLV) (d). Detection was made by enzyme immunochemistry (a, $\mathbf{c}, \mathbf{d}$ and $\mathbf{e}$ ), and by autoradiography (b). Islet homogenate was obtained from cyclophosphamide (CY)-untreated NOD mice (lane A), CY-treated NOD mice (lane B) and ICR mice (lane C). The TCA-treated tissue homogenate was obtained from the liver (lane L) and the spleen (lane S) of NOD mice. Lysate of NIH 3T3 fibroblasts infected with Mo-MuLV was used as a positive control (lane M). Immunoglobulin light and heavy chains were seen in $25 \mathrm{kDa}$ and $50 \mathrm{kDa}$ bands as a result of the immunoprecipitation (a and $\mathbf{b}$ ). As a molecular weight marker, pre-stained SDS-PAGE Standards Low Range (Bio-Rad, Richmond, Calif,, USA) was used. protein either in positive controls or in the islet homogenate obtained from CY-treated and untreated NOD mice (data not shown). This protein was not detected in the same analysis of TCA-treated tissue homogenate from the liver and the spleen of NOD mice (Fig. 2e).

In ICR mice, $30 \mathrm{kDa}$ gag protein $\mathrm{p} 30$ did not exist in islet cells as evidenced by the Western blot analysis using the method of enzyme immunochemical detection (Fig. 2c, d: lane C).

\section{Discussion}

We have previously shown that retrovirus-like particles were present specifically in the pancreatic Beta cells of NOD mice from gestation, and that some islet cells were positively stained with anti-retrovirus antibody (antiKiMSV antiserum) [2]. Ultrastructurally, these retroviruslike particles closely resemble type $C$ retroviruses in the Beta cells of streptozotocin-induced diabetic CD-1 mice [6]. In this study as well as in our present study, the budding of the particles to the extracellular space could not be observed. Such aberrant form of intracisternal type C particles have been already reported to exist in the Beta cells of NOD mice [7], and the ultrastructural features of these particles appear to be slightly different from those of more mature intracellular type $C$ retroviruses which have the capacity to bud extracellularly from pancreatic Beta cells in $\mathrm{C} 3 \mathrm{H}-\mathrm{db} / \mathrm{db}$ mice [8]. It is of interest that NIT-1 cells, a pancreatic Beta-cell line established from a transgenic NOD/Lt mouse, are shedding mature type $\mathrm{C}$ retrovirus from their surfaces [9]. In addition to type $C$ retroviruses, the existence of intracisternal type A virus particles (IAP) has been also reported [7], and CY treatment enhanced the number of the Beta cells containing intracytoplasmic type A particles, although it is difficult to determine the particle type from the figures illustrating this paper [10]. The results of our ultrastructural analysis indicate that most of the retrovirus-like particles in the Beta cells of NOD mice were type Crather than type A, and CY-treatment enhanced the expression of this type of virus particle. Using Western blot analysis, we have demonstrated, for the first time, that $\mathrm{gag}$ protein $\mathrm{p} 30$ derived from type $\mathrm{C}$ retrovirus existed in the islets of NOD mice and that this protein was increased by the administration of CY. CY has been known to accelerate the development of insulitis and overt diabetes in NOD mice [3]. These findings indicate that the retrovirus-like particle determined by morphological analysis is the retrovirus itself and plays an important role in the development of insulitis and overt diabetes.

There could be two possible mechanisms for the involvement of retrovirus in the onset of diabetes in NOD mice. Firstly, the retrovirus transcribed in the host gene may modify the expression of the host antigen on Beta cells, resulting in the initiation of immune responses against this antigen, which leads to the destruction of the Beta cells by an attack of immunocompetent cells. Secondly, the retrovirus might induce the aberrant expression of class II MHC antigen on the Beta cells, leading to the recognition of autoantigen(s) by helper $T$ cells and initiat- 
ing autoimmune responses $[11,12]$. It is unlikely that the retrovirus destroys Beta cells directly as seen in the case of encephalomyocarditis virus, because islet Beta cells in NOD mice seemed to be infected with the retrovirus persistently.

The mechanism of action of $\mathrm{CY}$ on retrovirus is unclear. But CY may increase the retrovirus by suppressing the immune response. At the same time, CY inhibits the synthesis of DNA. 5-Bromodeoxyuridine and 5iododeoxyuridine, which also inhibit DNA synthesis, are known to induce the expression of endogenous retrovirus in vitro [13]. Thus, CY might also induce the expression of endogenous retrovirus by inhibiting the synthesis of a factor which suppresses the expression of the virus.

In conclusion, retrovirus gag protein p30 existed in the pancreatic islets of NOD mice. The finding that CY treatment enhanced not only the expression of Beta-cell-specific retrovirus particles but also gag protein $\mathrm{p} 30$ in the islet, indicates that retrovirus is associated with the pathogenesis of diabetes in NOD mice.

Acknowledgements. We thank Dr. H.Fujino-Kurihara and Dr. A. Otsuka for helpful suggestions for this study. The anti-retrovirus antibodies were kindly provided by Dr. T. Kakunaga. This work was supported in part by the Scientific Research Fund from the Ministry of Education, Science and Culture.

\section{References}

1. Fujita H, Fujino H, Nonaka K, Tarui S, Tochino H (1984) Retrovirus-like particles in pancreatic B-cells of NOD (non-obese diabetic) mice. Biomed Res 5: 67-70

2. Fujino-Kurihara $H$, Fujita $H$, Hakura A, Nonaka $K$, Tarui $S$ (1985) Morphological aspects on pancreatic islets of non-obese diabetic (NOD) mice. Virchows Arch [Cell Pathol] 49: 107-120

3. Harada M, Makino S (1984) Promotion of spontaneous diabetes in non-obese diabetes prone mice by cyclophosphamide. Diabetologia 27:604-606
4. Maizel JV, Jr. (1971) Polyacrylamide gel electrophoresis of viral protein. In: Maramorosch K, Koprowski H (eds) Methods in virology, Vol 5. Academic Press, New York, pp 181-224

5. Laemmli UK (1970) Cleavage of structural proteins during the assembly of the head of bacteriophage T4. Nature 227: 680-685

6. Like AA, Appel MC, Williams RM, Rossini AA (1978) Streptozotocin-induced pancreatic insulitis in mice: morphologic and physiologic studies. Lab Invest 38: 470-486

7. Leiter EH, Wilson GL (1988) Viral interactions with pancreatic B-cells In: Lefebvre PJ, Pipeleers DG (eds) The pathology of the endocrine pancreas. Springer, New York Berlin Heidelberg, pp 85-105

8. Leiter EH (1985) Type C retrovirus production by pancreatic beta cells. Association with accelerated pathogenesis in $\mathrm{C} 3 \mathrm{H}$ $\mathrm{db} / \mathrm{db}$ ("Diabetes") mice. Am J Pathol 119:22-32

9. Hamaguchi K, Gaskins HR, Leiter EH (1991) NIT-1, a pancreatic Beta-cell line established from a transgenic NOD/Lt mouse. Diabetes 40: 842-849

10. Suenaga K, Yoon JW (1988) Association of Beta-cell-specific expression of endogenous retrovirus with development of insulitis and diabetes in NOD mouse. Diabetes 37: 1722-1726

11. Hanafusa T, Fujino-Kurihara H, Miyazaki A et al. (1987) Expression of class II major histocompatibility complex antigen on pancreatic B cells in the NOD mouse. Diabetologia 30: 104-108

12. Formby B, Miller N (1990) Autologous CD4 T-cell responses to ectopic class II major histocompatibility antigen-expressing single-cell islet cells: an in vitro insight into the pathogenesis of lymphocytic insulitis in non obese diabetic mice. Proc Natl Acad Sci USA 87: 2438-2442

13. Coffin J (1982) Endogeneous viruses. In: Weiss R, Teich N, Varmus $\mathrm{H}$, Coffin $\mathrm{J}$ (eds) Molecular biology of tumor viruses. RNA tumor viruses, 2nd edn. Cold Spring Harbor Laboratory, New York, pp 1109-1203

Received: 9 September 1991

and in revised form: 11 March 1992

Dr. C. Nakagawa

The Second Department of Internal Medicine

Osaka University Medical School

1-1-50, Fukushima, Fukushima-ku

Osaka 553

Japan 